\title{
The Male Gaze or Male Gays? From Romance to Bromance through Performances of Gender and Sexuality by two of Love Island's Favourite Characters
}

\author{
Sergio A. Silverio ${ }^{1,2}$ D $\cdot$ Catherine Wilkinson $^{3}(D) \cdot$ Samantha Wilkinson $^{4}$ (D
}

Accepted: 2 April 2021 / Published online: 18 April 2021

(c) The Author(s) 2021

\begin{abstract}
This paper draws on two favourite characters from British reality television show, Love Island 2018: Jack Fincham, a former stationery sales manager, and Alex George, an Accident \& Emergency [A\&E] doctor, to explore how heterosexual norms are constructed and challenged. We study the romantic on-screen relationships these characters have with the female contestants, and between the two male characters themselves through the notion of 'bromance'. Through a textual analysis of the spoken words and physical interactions between characters in episodes forming the fourth series of Love Island and analysis of social media posts and articles in popular press outlets, we use the notion of gender performativity to explore how these characters perform both hegemonic and, what we argue is, 'threatened' masculinity. We use the 'Male Gaze' to methodologically lens the performances by characters and their romantic interactions on the television show. In particular, we focus on Jack and Alex's budding relationship and the condemning of this relationship by the public amid Alex's termination of his romantic relationship. The decision by Alex to end this relationship led to many viewers questioning his sexuality, with specific reference to his adoration for Jack. Whilst broadly, this paper contributes to debates on the sociological potential of reality television shows, such as Love Island, its specific contribution is to a small, but growing body of international scholarship on homosocial relationships and male love stories in television and film. With this paper, we also contribute towards redressing the marginalization of women within the study of bromance.
\end{abstract}

Keywords Bromance $\cdot$ Femininity $\cdot$ Masculinity $\cdot$ Performance $\cdot$ Reality television $\cdot$ Sexuality

\footnotetext{
We dedicate this paper to television and radio presenter, actress, and Love Island host, Caroline Flack (9 November 1979 - 15 February 2020), whose life was cut - deplorably - short, and whose wish was that in a world where we can be anything, we choose to be kind.
}

Sergio A. Silverio

Sergio.Silverio@kcl.ac.uk

Extended author information available on the last page of the article 


\section{Introduction}

This paper draws on two favourite characters from Love Island 2018: Jack Fincham, a former stationery sales manager and Alex George, an Accident \& Emergency $[A \& E]$ doctor, to explore how heterosexual norms are constructed and challenged. We study both the romantic onscreen relationships these characters have with the female contestants with whom they are 'coupled-up', and between the two male characters themselves through the notion of 'bromance' ("an emotionally intense bond" between straight men; DeAngelis, 2014:1). Media representation of men and masculine identities has, in more recent years, created a space for predominantly heterosexual white men to engage in platonic intimate relationships with other men. The performance of bromance has long been studied (Sedgwick, 1985), and its notoriety as a landscape for study lies partly in its marketability (DeAngelis, 2014). Indeed, bromance has become a sub-genre of romantic narrative in its own right, and is often contested as to whether it is a performance of 'straight' male behaviour or not (Corwin, 2016). Davis (2014) states film-based bromances often carry greater narrative and emotional weight than the relations presented between a man and his girlfriend or wife. Notably, there is a marginalization of women within the study of bromance (Thompson, 2015). It is for this reason, in this paper we focus also on the couplings between Jack and Dani, and, Alex and Alexandra, rather than solely on Jack and Alex themselves. By doing so we increase the scope of this paper to address the effects on all characters and not just on those who are male.

Through a textual analysis of episodes forming the fourth series of Love Island and analysis of content on social media and popular press, we use the notion of gender performativity (Butler, 1988; 1990) to explore how Jack and Alex perform both hegemonic and threatened masculinity (a gender identity that goes against societal norms dictating that men should be masculine and powerful). In particular, we focus on Jack and Alex's budding bromance and the condemning of this relationship by the public amid Alex's termination of a romantic relationship with female contestant, former make-up artist, Alexandra Cane. By public, we should clarify, we mean the 'viewing public', i.e. those who watched the show, and in some cases took to social media to comment about the show and the characters. Alex's decision led to many viewers questioning his sexuality, with reference specifically to his adoration for Jack. Interestingly, whilst Jack and Alex's bromance had initially been watched fondly by the public (as seen on social media posts and by the fact they were both retained on the show when others were voted off), Alex's newly acquired single status led viewers to denigrate this bromance, for the threat it might bring to Jack's relationship with female contestant Dani Dyer. With this paper we hope to shed further light on the ways bromantic relationships are viewed and received by audiences. We do so through working at the intersection of (gender) performativity theory from Butler $(1988 ; 1990)$ and Goffman (1959), and the conceptualisation of types of masculinity from the Brannon Masculinity Scale (BMS; Brannon \& Juni, 1984; David \& Brannon, 1976).

This paper is structured as follows. First, we collate literature on performing gender and sexuality and underpin this with performance theory from both Butler 
(1988; 1990) and Goffman (1959). We then move on to explain our theoretical approach to masculinity using the Brannon Masculinity Scale's (Brannon \& Juni, 1984; David \& Brannon, 1976) four types of masculinity, before providing an overview of debates on masculinity and friendship. After this, we provide snapshots of couplings, which the audience gave the following conflating portmanteaux: 'Jani' (Jack and Dani); 'Alex ${ }^{2}$ ' ['Alex Squared'] (Alex and Alexandra); and 'Jalex' (Jack and Alex). We then outline the materials and methods, discussing our approach to the textual analysis of Love Island episodes, and our use of Mulvey's (1975) 'Male Gaze', as a lens through which we conducted our analysis. In the substantive analytical section of this paper, we present findings from a textual analysis of episodes forming the 2018 series of Love Island, taking into account the different ways in which characters can be gazed upon by other Love Island contestants and the viewing public, as well as comments made on social media by viewers, and reaction from the press in an online ethnography. After uniting our analysis with our integrated theoretical framework in the discussion, we conclude by outlining the contribution of this paper, not just to debates on the psychosociological potential of reality television shows, but also to a small but growing body of international scholarship (e.g. Benson, 2017; Brook, 2015; DeAngelis, 2014; Nettleton, 2015; Raphael \& Lam, 2017; Sedgwick, 1985) on homosocial relationships and male love stories in television and film.

\section{Performing Gender and Sexuality}

The sociological literature on performing gender and sexuality has predominantly been characterized by two alternative discussions of performance, those of Judith Butler (1988; 1990), a philosopher who has heavily influenced the social sciences; and sociologist and social psychologist Erving Goffman (1959). We use Butler's (1988; 1990) notion of gender performativity to explore how masculinity, and in doing so, femininity, are performed by Love Island characters Alex and Jack. Gender is a heavily contested concept (Silverio, 2018), but most accept Butler's (2011) argument that being a (wo)man is not internal; that is, gender is not innate or natural, but we are assigned a gender at birth based on visible external sex organs. Therefore, gender is not a 'given', rather, gender is continually produced and reproduced, performed and reconstructed; and is ultimately a social construction.

Butler (1990) argues normative gender identities are inextricably embedded and produced within hegemonic representations of heterosexuality (Connell, 1987; Renold and Ringrose, 2008). This is not a 'choice', it is learned behaviour in relation to socially constructed 'norms' (Kohlberg, 1966). Butler (1990) posits there is no gender identity behind the expressions of gender, but identity is constituted performatively by such constructions. Like many contemporary social scientists, we adopt the same stance that both gender, and sexuality, can be, and are, performed.

Gender then, is not a stable identity; instead, it is culturally constructed through the "repeated stylization of the body, a set of repeated acts... that congeal over time to produce the appearance of substance, of a natural sort of being” (Butler, 1990:33). These acts are not singular; rather they are reiterative (Butler, 1993). As 
these acts are continually repeated, there is space for transgressions and "slippage" (Butler, 1993:122).

There is a body of scholarship which questions what is 'real' and 'authentic' in reality television shows (e.g. Mast, 2016), appreciating that performance can be curated by both producers and the characters of these shows. For instance, Skeggs (2009:626) discusses the "self-performance" of individuals on reality television. However, whilst it is obvious that some scenes on 'reality' television shows are staged and perhaps scripted, Skeggs and Wood (2008) claim they still offer us insight into what 'actually' happened as a result of the initial set-up. Our decision to use of the term 'character' throughout this paper is a deliberate one. We suggest performances of gender roles are not only conscious, as Butler $(1988 ; 1990)$ would suggest, but are being enacted with an audience in mind (as in Goffman, 1959). Performance, for Goffman (1959), is characterized by aseries of dramaturgical metaphors, including the world as stage; stage management; setting; front and back regions; guises; and stage props, amongst others. This line of thought appreciates that interaction is an engagement between the individual and the audience, to whom individuals perform, and who interpret the individual's actions. This dramaturgical approach is concerned with strategic impression management and primed improvisation in everyday life, through which individuals typically communicate their intentions, circumstances and relationships. This is achieved by live 'performance' on the 'front stage' spaces, and inaccessible, perhaps more natural, behaviour in 'back stage' spaces where the microphones are off (see Wilkinson, 2017). As we are analysing a reality television show, we are concerned with the front stage performances only, since we did not have access to the 'back stage'; that is, those times when microphones were off, and performers dropped their act.

Whilst Butler (1988; 1990; 2011) and Goffman's (1959) approaches to performance have typically been deployed individually (for exceptions see Demant \& Järvinen, 2006; Malbon, 1999; Wilkinson, 2019), through working at the intersection of the theoretical perspectives of both scholars we hope to offer a more nuanced understanding of the romantic and bromantic relationships performed by Jack and Alex. In sum, we use Goffman's (1959) understanding of performance to argue that characters may be playing different roles from who they 'really' are, whilst also emphasizing gender as performative: it is staged in our lives and daily practices (Butler, 1990).

\section{Theorizing Masculinity and Male Friendship}

Masculinity has long been discussed in terms of what it comprises (Bem, 1974; Connell, 1995), how it has been contrasted against females and femininity (Apollon, 1993; de Beauvoir, 2011/1949; Ging, 2019), and how it has been used to maintain gendered males as the hegemonic power in society (Budgeon; 2014; Connell, 1987; Ging, 2017; Paechter, 2006; Schippers, 2007). According to Connell (1995), there is a hierarchy of masculinities. At the top of this hierarchy is 'hegemonic masculinity', with qualities including heterosexuality, whiteness, physical strength, and the suppression of emotions, such as sadness. Below this, is 'complicit masculinity'. 
This phrase refers to men who may not fit all of the characteristics of hegemonic masculinity, but equally they do not challenge it, as they receive some of the benefits of being male. We then have 'marginalized masculinity', in which men cannot access all the features of hegemonic masculinity, due to factors such as their race or disabilities, but still withhold emotions and may display physical strength (Connell, 1995). At the bottom of Connell's (1995) hierarchy of masculinity is 'subordinate masculinity', in which men exhibit qualities that are oppositional to hegemonic masculinity, such as being physically weak, and showing sadness. Effeminate and gay men are considered exemplars of subordinate masculinity (Connell, 1995). In theorizing masculinity and the relationships which males maintain, it is important to recognise the historical contestation of 'homosociality' (male-male relationships or 'bromances') as performances of 'straight' or 'homosexual' behaviour (Corwin, 2016). For example, Lipman-Blumen (1976) first explained homosociality as the social preference for one's own sex, as compared to Sedgwick's (1985) interpretation which argues homosociality as bonding between men, which is always predicated by a fear, hatred, and ultimate rejection of homosexuality. This, however, does not preclude homosocial desire spanning the whole spectrum of relationships, from the platonic to the erotic. This contestation of 'homosocial' as anything other than 'straight' male behaviour has continued to the present day with scholars divided on the matter (see Clarkson, 2006; Corwin, 2016; Kilianski, 2003; Wade \& Donis, 2007).

Bringing together these ideas of defining masculinity, its use in maintaining masculine privilege, and its abuse in projecting the feminine as the inferior gender identity, is David and Brannon's (1976:12) classic theorization of four themes that comprise the male sex role. A recent review of masculinity scales (Thompson Jr. \& Bennett, 2015) suggests the Brannon Masculinity Scale (Brannon \& Juni, 1984; David \& Brannon, 1976) remains one of the most useful conceptualisations of masculinity, and importantly "provides no appraisal of the importance of sexuality or men's privilege” (Thompson Jr. \& Bennett, 2015:117), which is beneficial to our analysis of close male friendships or 'bromance' depicted in Love Island, as it purposefully avoids the Lipman-Blumen/Sedgwick debate. The first of these four masculinities is: 'No Sissy Stuff', suggests a distancing of one's self from femininity, through homophobia, and avoidance of emotions, whilst stigmatizing stereotypical feminine characteristics and qualities, such as openness and vulnerability. The second typology is 'The Big Wheel', where an individual strives for achievement and success and focuses on competition to achieve an idolized role model status. Thirdly comes 'The Sturdy Oak', which is concerned with, staying composed and in control, whilst appearing to be tough. Fourth, 'Give 'Em Hell!', where individuals act daringly or aggressively to the point of violence, to become dominant. The Brannon Masculinity Scale (Brannon \& Juni, 1984; David \& Brannon, 1976) present these themes in recognition of the role society encourages males to adopt and play out, a false front that men must fake (or perform; Butler, 1988, 1990; Goffman, 1959) in order to 'make it' or be a societal success. This typological theorization of masculinity is still relevant in contemporary society (Thompson Jr. \& Bennett, 2015). Though appreciation of gender fluidity has become more widely spoken about and accepted, 
the expectation of the performance of gender roles has seemingly been maintained (Clarkson, 2006; Kilianski, 2003). Sex-linked gender role adherence has more recently been suggested to have possibly even crystalized in what Pickard (2018:11) calls the "sexual double standard" - whereby women are expected to engage in sexual relations, but simultaneously "protect their reputations from being perceived as 'easy'; 'whore'; 'slag/slut'” which, Pickard comments, are "insults that have no male equivalent". We use the Brannon Masculinity Scale's (Brannon \& Juni, 1984; David \& Brannon, 1976) four types of masculinity as a framework for our analysis, considering them important in understanding the construction and stratification of masculine power and privilege (Anderson, 2005; Ging, 2017; 2019).

A critique of both Connell's (1995) work and the Brannon Masculinity Scale (Brannon \& Juni, 1984; David \& Brannon, 1976) is the suggestion that deviation from the traits of hegemonic masculinity is considered a failure (Chu, Porche, \& Tolman, 2005; Wade \& Donis, 2007). Some practices undertaken by men (e.g. displaying emotion) may, from the perspective of Connell (1995) and the Brannon Masculinity Scale (Brannon \& Juni, 1984; David \& Brannon, 1976), be interpreted as constituting a threat to dominant notions of masculinity, and in turn result in a loss of masculine status and self-esteem (Harder and Demant, 2015). However, this is not entirely adequate to fully understand or interpret how persons do masculinity. More recent work by Anderson (2005), in the context of the construction of masculinity among heterosexual male cheerleaders, can be praised for promoting a more inclusive understanding of masculinity. Rather thaninterpreting men's engagement in practices such as care as a failure to comply with the tenets of orthodox masculine construction, authors such as O'Neill (2015) contend they are enacting, what she terms, 'inclusive masculinity'. That is, an alternative form of masculinity that is not based on the exclusion of femininity, and related symbols and practices (i.e. the model of masculinity presented by Connell, 1995), but rather open to (inclusive of) enactments and practices traditionally associated with femininity, including displays of care, brotherly love, and emotions.

These more emotional displays stretch the traditional understanding of masculinity and can be most evidently found in male-male friendships. Previous work has found that masculinity is negotiated between friends, be they at scholastic settings (Ripley, 2018; Robinson, White, and Anderson, 2017), in sports (Magrath, 2016), or even depicted in film (Brook, 2015). These male friendships - some of which are portrayed as bromantic relationships - can be performed in wider contexts such as that of race (Jackson, 2012; Jackson and Wingfield, 2013), but ultimately lead to a stretching of traditional masculine expectations to incorporate more homosocial performances (see Sedgwick, 1985) which are in turn more relaxed in their expectations of striving for, and achieving hegemonic masculinity (see also Anderson and McCormack, 2018).

Whilst we use the Brannon Masculinity Scale (Brannon \& Juni, 1984; David \& Brannon, 1976) in this paper we acknowledge that individuals may not neatly fit the model and that there is some scope for their performances (Butler, 1988, 1990; Goffman, 1959) to shift or sit across the various types of masculine portrayal. 


\section{Materials and Methods}

Our methodological approach to this study was a combination of analysis of series four of Love Island, and analysis of the public and media response to this. We chose to use a multi-method approach in an attempt to satisfy each gaze Mulvey (1975) sets out in the 'Male Gaze', hereby capturing how the characters viewed themselves; how the characters we are writing about were viewed by other characters on the show; and how the selected characters were perceived by the viewing public. We detail the multi-method approach adopted herein.

\section{Textual Analysis}

There is a long history of using visual media such as film and video as means of gathering data in textual analysis methods (Buckingham, 2009). In this study, we used a theory-driven textual analysis approach. The dataset consisted of 59 one-hour episodes comprising the fourth series of Love Island. To increase inter-rater reliability and the validity of the analysis, each episode was reviewed by at least two researchers (see also Cahill \& Papageorgiou, 2007; Caldwell \& Atwal, 2005). Each episode was viewed as a unit of analysis.

We used a coding template grid to describe visual data and to record verbal data verbatim and document each episode number and the time of key moments. In line with the theory-driven approach to textual analysis we adopted, we produced a coding frame based on the theoretical framework and developed initial coding categories using David and Brannon's (1976) four types of masculinity 'No Sissy Stuff'; 'The Big Wheel'; 'The Sturdy Oak' and 'Give 'Em Hell!'. Abiding by this coding frame did not preclude "additional discovery-oriented work" within the episodes (Derry et al., 2010:16), as we documented any references to gender, sexuality or bromance which we did not consider to fit into any of these four types in a section headed 'Any other comments?'. We documented only coded incidents concerning the three couplings at the focus of this paper 'Jani', 'Alex ${ }^{2}$ ', and 'Jalex'. References coded consistently by both reviewers were accepted. There was a high degree of consistency between the researchers' observations. If there were any areas of discrepancy, the episode would have been shared with the third member of the research team as a means to guard against inherent bias, and to become reflexively more aware of any assumptions.

We also used Mulvey's (1975) 'Male Gaze' to methodologically lens the performances by characters, and their romantic interactions on the show. Mulvey's (1975) article 'Visual Pleasure And Narrative Cinema' introduces the theoretical concept of the 'Male Gaze' as suggestive of the overlapping lenses with which the character is being watched: The look from the other characters; the look through the camera; and the look of the audience, which, when overlaid, produces the 'Male Gaze'. The Male Gaze has been used in the critical analysis of films and advertisements, typically in terms of the way in which images of women resonate with female stereotypes shaped by the male gaze (Brandt and Carstens, 2009). The notion of the gaze has been adapted in this paper from Laura Mulvey's (1975) 'Male Gaze' to reflect 
whereby the characters we discuss - principally Jack and Alex - have been subject to analyses by each other (their comments to and about one another documented in our textual analysis); and by other characters on the show (also highlighted in our textual analysis). The third gaze - that of the viewing public - also subjected Jack and Alex to a social analysis (detected and presented here as our online ethnography).

It is important to recognize that a gaze differs from a look, due to the implication of the insertion of power and possession, whereby: "to gaze implies more than to look at - it signifies a psychological relationship of power and sexuality in which the gazer dominates the object of the gaze" (Schroeder and Zwick, 2004:30). However, what is interesting in the context of Love Island, is that both males as well as females are under scrutiny by a largely female viewing audience who reside in the phallogocentric, masculinist West. Thus, the focus of the gaze is displaced from strictly the female characters and the sexualization of them, to encompass the male characters and their sexuality, which, as Jacobsson (1999:25) suggests, is a switching of normal viewing in a way which "[codifies] a male character as an erotic object" and the "female character as the gaze". This in itself "becomes difficult due to connotations and codification into the language of the dominant patriarchal order" (Jacobsson, 1999:25), therefore presenting both genders as an object of sexual desire, which in turn can attract sexualization, internalized as shame by performing (fe)males (Silverio, 2019). This description resonates with Sturken and Cartwright's (2001) view that the desires of spectators are caught up in the relationship of power, and that the spectators become more powerful than the object of their gaze.

Our approach to combining the textual analysis with this theoretical framework fits well with the 'craft' of visual research which, as Spencer (2010) argues, requires a balance between inductive forces - allowing the collected data to speak for itself, and deductive forces - structuring, ordering principles derived from theoretical models and concepts.

\section{Online Ethnography}

Online ethnography was secondary to our own analysis and interpretation of the Love Island series. As such, we used data from the online ethnography to triangulate our key findings from the textual analysis. This enabled us to complete our 'gaze analysis' (see Mulvey, 1975) by adding the final lens of the gaze from the viewing public.

As a research platform, online sites have been celebrated as providing a point of access for naturalistic data, which has the ability to accurately depict the lived realities of a range of individuals (Rokka, 2010). Online data can provide a rich source of data that has been written or created without the purpose of research in mind (Wilkinson \& von Benzon, 2021). This is important as it means that the data collected is not being produced with an attempt to please a researcher, or to fit into certain themes pre-determined by the researcher (von Benzon, 2018). Undertaking an online ethnography, we visited Twitter and Instagram, acknowledging that these are the websites Love Island followers frequent and post content regarding the show. Fans also use these platforms to 'follow' Love Island characters on accounts that are 
managed by friends or agents when the characters are in the villa, and then by the characters themselves upon exiting the villa. We 'lurked' (Kozinets, 2010) on these websites and selected comments to be used as data to support our textual analysis.

On Twitter we searched for Tweets that @ tagged or \# hashtagged the Love Island characters Jack and Alex. We also searched for tweets that used the key words bromance and Love Island together. Further, two members of the research team followed the Love Island characters on Instagram whilst the show was broadcast. On Instagram we visited the pages of Jack and Alex and scrolled through comments on their posts. Because of the lack of search function for comments on Instagram it was not possible to employ a search strategy, rather to 'lurk' and observe content. We typed out all content verbatim into the relevant sections of the coding template grid.

Whilst opening up new opportunities for undertaking research, there has also been much debate regarding the ethical codes of conduct for online studies (Rokka, 2010). For instance, there is an issue of consent, and indeed informed consent, in research that uses publicly available personal content. Consideration needs to be given to whether, or not, the writers / creators of online content should be protected (von Benzon, 2018; Wilkinson \& von Benzon, 2021). We follow the argument of other scholars that it is not necessary to seek permission to use written comments posted in a virtual community, as they are ostensibly public (e.g. von Benzon, 2018). In the presentation of results, we do not attribute a name to these comments.

\section{(Un)couplings: Snapshots of Romance, Breakup, and Bromance}

We present the below snapshots of the couplings 'Jani', Alex ${ }^{2}$, and Jalex on which this paper focusses to provide context for thereader. There is a marginalization of women within the study of bromance (Thompson, 2015). This is problematic as there is evidence that bromances and romances can conflict (see Robinson, Anderson, \& White, 2018). This can be understood when considering that one of the ways in which hetero-masculinity is reaffirmed in a bromantic relationship is via the presence of women who are used to reaffirm sexual boundaries (DeAngelis, 2014). It is for this reason that in this paper we focus also on the couplings between Jack and Dani, and Alex and Alexandra, rather than solely on Jack and Alex themselves.

\section{Jani}

Jani, as the couple Jack and Dani were coined by Love Island fans, were celebrated for their 'fairytale love story' (ITV plc, 2019). In the initial coupling up on Day 1 of the series, Dani, a former barmaid, 'stepped forward' for Jack, a former stationery sales manager (in the show, 'stepping forward' is an action used to express romantic interest). Jack chose to couple up with Dani, and they remained coupled up for the entire series. They faced some challenges, such as Jack confessing to cheating on his previous girlfriends, and one of Jack's ex-girlfriend's arriving to meet him at Casa Amor (another villa on Love Island where some existing Islanders visit and meet some new contestants with the opportunity to recouple before returning to the villa. It is an intervention used by show producers to test relationships on the show. 
However, Jack remained faithful whilst in Casa Amor and returned to the villa to tell Dani he loves her. In doing so, he transitioned from a womanizing 'Give 'Em Hell!' type masculinity, to a 'Sturdy Oak' (David and Brannon, 1976). This transition from hell-raising masculinity to a quelled masculinity has also been noted in more modern literature, which has suggested the influence of partners is important for men to stabilise as a partner, provider, and/or father (Anderson, 2005; Kilianski, 2003; Wade \& Donis, 2007), suggesting the 'Sturdy Oak' typology is enacted even in modern, and the more egalitarian heterosexual relationships which we recognise in today's society. The expression of love from Jack was a sentiment which Dani returned, and the couple went on to win the series.

\section{Alex $^{2}$}

Alex, the self-labelled 'Dr. Love', is a 'Big Wheel' character of David and Brannon's (1976) four themes, as he strives for achievement and success in life and love. Alex had many failed attempts at finding romance in the earlier episodes of Love Island with a number of female characters. Later in the series, much to the public's delight, Alex coupled up with makeup artist, Alexandra Cane. However, despite a promising start, including Alex affectionately labelling himself and Alexandra 'Alex ${ }^{2}$ ' and a night away in the hideaway (a retreat where Love Island couple's go away from the gaze of other contestants, but still in view of the public), Alex ended the relationship with Alexandra. Alex's reasoning was that he was concerned with how fast their relationship was moving and, in doing so, performed a 'No Sissy Stuff' (David and Brannon, 1976) masculinity in his simultaneous rejection of Alexandra and emotional avoidance. In terms of this transitional performance of masculinity (Butler, 1988, 1990), the termination of this relationship shocked many viewers as they took to social media to question Alex's sexuality, with many paradoxically labelling him 'gay'. This is not uncommon when we reflect on published literature regarding media representations of male identities (see Clarkson, 2006), but again suggests that masculinity is fragile and requires constant maintenance to ensure one is not portrayed as anything bar fulfilling a traditional masculine 'norm' (Anderson, 2012; Arciniega et al., 2008).

\section{Jalex}

An unlikely bromantic relationship formed between Jack, a self-confessed 'Jack the Lad' and the smart and sensible Alex, in direct opposition to a 'No Sissy Stuff' (David and Brannon, 1976) portrayal of masculinity. Often masculinity is a facet of identity which is developed among friends from a young age (Chu et al., 2005; Flood, 2008), and here, the depiction both Jack and Alex provide of themselves has been cultivated over time and is presented on screen. This bromance was evident to viewers through their embraces, including confessions such as "I love you to death, mate" and Jack calling Alex "a peng sort" (Essex - a county in South East England - slang used to describe someone a person finds attractive) to which Alex replied: "thanks Jack, you're a sort as well". This was quickly picked up on by popular press, with PopBuzz (2018) noting that Jack and Alex's bromance is "melting hearts 
everywhere" and more dramatically "its [sic] actually the greatest love story ever told". There were calls from viewers on social media for ITV to bend the rules to allow a bromance to win the show. While the male-male bond between Jack and Alex had been watched fondly by viewers, at the point of Alex's termination of his relationship with Alexandra, Alex faced backlash. Alex's decision also tarnished the 'Jalex' bromance, which could be argued to now resemble a 'Give 'Em Hell!' (David and Brannon, 1976) performance of masculinity with the bromantic partners being suspected of seeking adventure over romantic interest and remaining loyal to the females with whom they had earlier coupled up.

\section{Results}

Herein, we provide the results of a textual analysis of the fourth series of Love Island and reactions to these episodes on social media and in the press, focusing on the abovementioned three 'couplings'.

\section{From Romance to Bromance - Performances of Gender and Sexuality}

In the first episode of Love Island, we were introduced to the original line-up of 'Islanders'. It is also in the episode that viewers see the first 'coupling up' of contestants. Upon meeting each male contestant, the female contestants were instructed to 'step forward' to signify that they are interested in coupling up with that person. If more than one female contestant stepped forward, the male contestant had to decide who they wanted to couple up with. Both Dani and fellow contestant Samira stepped forward for Jack, but Jack chose to couple up with Dani, saying: "I think Dani's lovely, I'll pick Dani". On Day 7 the couple went on their first date, with Jack confessing that he sees a future with Dani: "I want something to happen. Take you home, meet all my family and that". Throughout the series, Jack and Dani's relationship strengthened, and after three weeks in the villa, Jack asked Dani to be his girlfriend. They were the only couple to remain coupled up from Day 1 to the final.

Returning to the 'first coupling', none of the female contestants stepped forward for Alex. Because of this, after all contestants had coupled up, Alex coupled up with Samira, who had also not been selected. Alex was quick to emphasize early on that his relationship with Samira was only a friendship and did not have romantic potential. Viewers accepted this since neither contestant selected to be coupled up with the other. Throughout the series Alex had opportunities with other female contestants, namely: Megan Barton-Hanson; Ellie Brown; Charlie Williams; and Grace Wardle, but none of these relationships materialized for various reasons, including the female contestants choosing to couple up with another male contestant; a lack of interest in pursuing anything romantic by either party; or in the case of Charlie, Alex choosing to return to the Villa from Casa Amor with Grace, leaving Charlie to be 'dumped' from the Island (to be voted off the show and consequently exit).

There were certain instances throughout the episodes where Alex's sexuality was called into question. In an episode where contestants were instructed to guess which 
fact belonged to which fellow Islander, it was revealed that Alex had a "threesome with his friend and a girl" (that being whereby three people engage in sexual activity together), because of the way this is phrased it is presumed by the viewing audience that his friend is male. Further, during an episode in which the Islanders were acting out scenes from movies, Jack and Alex were paired together and acted out a romantic scene which led to a kiss. In a classic Mulveyan gaze (Mulvey, 1975), the camera panned to the confused faces of female Islanders Ellie and Samira. Afterwards, Jack - now commenting on his own presentation in that scenario - said to thecamera "I thought,listen, let's put $100 \%$ effort into it, but let's not - let's not actually kiss. I went in for it and he'd gone straight for the lips, like fucking hell Alex". Speaking to the camera also, Alex said: "I think the romance almost got the better of us, but if anything, Jack was the one who was a bit shyer, I'm not offended it's fine”. What is interesting here, is the complete opposition to the 'No Sissy Stuff' (David and Brannon, 1976) masculinity typology, which both characters can be considered to have performed at different times throughout the show, due to the physicality of the interaction. Physical interactions between two or more heterosexual men have been cited in masculinity literature as boundary pushing in terms of performing a traditional masculine role unless it is enacted as an action which has been or will be expressed among or with women (Lupton, 2000), and can lead to outside questioning of the performers sexuality (Brook, 2015), or in some cases, lead to the exclusion of these men (Harder and Demant, 2015), so as not to challenge the hegemonic patriarchal status of the extant group.

On Day 39, Alexandra entered the villa and chose to go on a date with both Alex and Jack Foster (known by viewers as 'new Jack'). On Day 40 the Islanders recoupled, this time with the girls choosing which boy they would like to couple up with. Alexandra chose to couple up with Alex. On Day 50, Alex and Alexandra left the villa to go on a second date in a picturesque undisclosed location. During this date Alex confesses "I'm someone who, if things move very quickly, I panic, and I run away a little bit". However, Alex ends the date on an optimistic note saying: "That blip we've had, is done. We've got over that. We're continuing to grow and I'm very excited".

Later in the series, Alex and Alexandra were selected by fellow Islanders to spend a night in the hideaway. Alexandra dressed in a thong and bra complete with black lacey dressing gown. When Alex saw Alexandra, he said: "Shit. Why you wearing that? Why's she wearing that?" Alex's reaction was condemned by Cosmopolitan magazine as "a mess" (see Lewis, 2018) and left viewers confused. Once again, we see the gaze of the viewing public (see Mulvey, 1975) at this point, whereby one viewer took to Twitter to say: "Alex is so sauceless. Alexandra did up sexy sexy and all he did was kiss and cuddle her [sic]?" However, although it was not broadcast, Alexandra tells the female Islanders that she and Alex shared an intimate moment in the hideaway: "he grabbed my hand, opened his shorts and [laughter]". In a conversation after the sexual encounter Alex - commenting in a Mulveyan (Mulvey, 1975) way on his friend Jack - tells Alexandra "no pressure, take things slow... we're not going to be Jack and Dani, not yet". Later in the episode, when the male Islanders are sat together, Jack says to Alex "a little birdie told me that someone may have touched your Johnson' (slang for penis). After finding out that Alex had reached this 
milestone, and in a shared moment of 'Big Wheel' masculinity (David \& Brannon, 1976), focusing on achieving an idolized role model status, Jack declared: "I want to do a toast to my good friend Alex, I love you very much and things are moving in the right direction".

Doubt was cast on Alex and Alexandra's relationship amid the arrival of four new Islanders: Stephanie Lam; Laura Crane; Paul Knops; and Josh Mair, with Alex admitting to fellow contestants that he wanted to get to know Laura: "She is the kind of girl that's quite similar to what my type would be". This led Alexandra to question Alex about this attraction: "I thought you would like Laura. Just insecurities, because you didn't cuddle me last night”. Alex's attempt to pursue Laura led Alexandra to ask new contestant Paul for a kiss. However, in the recoupling Paul coupled up with another contestant, Laura Anderson, leaving Alex to couple up with Alexandra. Following this incident, Alexandra is seen to confide in fellow Islanders saying: "Alex and I, I feel like we're just friends".

After taking advice from Jack and Dani, in an iconic Love Island moment, Alex attempts to reignite the connection with Alexandra by engaging in role-play, pretending they were meeting for the first time. Whilst we have viewed all encounters on Love Island through a lens of performance, this scene was a performance in the sense that all characters and spectators were engaged in "shared pretense" (Searle, 1979:71), as other Islanders were 'in on it'; they are aware of the play-acting and thereby thickened the lens ascribed to other characters who were onlookers to this charade (Mulvey, 1975). Alex assumes the fantasy of chatting Alexandra up in a bar and she plays along, pretending that she has a bruise which requires the Doctor's attention. In a notable - though albeit temporary - transition from 'No Sissy Stuff' to a 'Sturdy Oak' (David \& Brannon, 1976), Alex then says: "I heard you have a broken heart, so I just wanted to come here and fix it”. The pair then kissed, initiated by Alex. This moment was viewed excitedly by spectators Jack and Dani, who cheer and rejoice.

On Days 54/55 all remaining couples, including Alex and Alexandra, had their 'final date', organized by the production team. However, the moment the viewers had been waiting for was somewhat anti-climactic, as Alex seemed more besotted with the Ferrari he was driving as part of the date than Alexandra herself. After the date, Alex confided in Jack saying, "I don't have the feelings that I should [for Alexandra]". In another scene with Jack and Dani, in which Alex tells Dani he finds new girl Laura "hot", Dani tells Alex: "be a little bit more of a man and actually see if she's [Alexandra] okay" to which Alex, clearly insulted at having his masculinity threatened by Dani's remark, replies: "hang on Dani, I have been a man". Alexandra proceeds to confront Alex, accusing him of being distant from her. It transpires Alex's distance has been intentional, because he was trying to slow things down between them. This leads Alexandra to accuse Alex of leading her on. She told him: "I think you're trying to come across as this super nice guy who knows what they want, you haven't been honest with me".

Despite being a popular character on the show, Alex's denouncing of a relationship with Alexandra led to backlash on social media, including a barrage of abusive tweets and comments on his Instagram account. Whilst his actions led some media outlets to question "Was Dr. Alex ever really looking for love after all?" (e.g. Radio 
Times, see Griffiths, 2018); it led many viewers to question Alex's sexuality. Alex's Instagram page is replete with examples of such questioning. Here are a few comments made by the public on a photograph of Alex and Alexandra: "he would rather couple up with Jack he need [sic] to think about who he is..."; "I think is gay... not been homophobic... just he think he is trying to be something that he is not... maybe is in to one of the guys on the island [sic]!!!". Moreover, on a photograph of Alex and Jack embracing in bed together comments include: "for someone that don't like affection, you seem to give Jack more than you have to any woman that has give you attention [sic]... \#GayMaybe??”, and: “I'm 10000\% sure he's gay”. Here, viewers are deriding Alex for transgressing traditional masculine norms and in doing so conflating the bromantic portrayal as acts of homosexuality, further scorning the 'Jalex' relationship for not keeping within the already blurred confines of male-male friendships portrayed on the show.

\section{Discussion}

Our analysis has found that, in the depiction of the bromantic relationship between Alex and Jack, traditional hegemonic masculinity is seen to be threatened (Connell, 1995). To explain, there are certain attributes of femininity displayed throughout their relationship, such as emotional closeness and emotional support between the two male characters. This, we argue, is because bromances provide opportunities for gender subversion (Brook, 2015). However, from the public's reaction to Alex amid his termination of his relationship with Alexandra it can be seen that any presence of femininity, or what some may argue is subordinate masculinity akin to homosexuality (Connell, 1995), raises a risk for men in performing (Butler, 1988, 1990; Goffman, 1959) hegemonic masculinity (see also Corwin, 2016). This can lead them to adopt the more 'toxic masculinity' typologies such as 'Give 'Em Hell!' and 'No Sissy Stuff' (David \& Brannon, 1976). By 'toxic masculinity', we mean - using Ging's explanation (Ging, 2019: 645) - a masculinity which promotes "extreme misogyny and proclivity for personal attacks". In particular though, part of the negative reaction of viewers to this scenario was due to the ways in which they believe bromances and romances can conflict (see Robinson, Anderson, \& White, 2018); that is, some viewers believed a single 'Give 'Em Hell!' (David \& Brannon, 1976) Alex could pose a threat the much-loved coupling of Jack and Dani. This can be argued as portraying what Sedgwick (1985) describes how the triangle of desire works, whereby one male jepordises another male's chance with a single female, however the difference here is that Alex is not competing for Dani, but rather, is competing with her for Jack's attention - which can be codified as "slippage" from the hegemonic masculine role (Butler, 1993:122), or in fact simply a display of the complexity which underpins modern constructions of mixed-sex social networks and relationships (see also Arciniega et al., 2008; Flood, 2008). This can be understood when considering that one of the ways in which hetero-masculinity is reaffirmed in a bromantic relationship is via the presence of women who are used to reaffirm sexual boundaries (DeAngelis, 2014), and in the context of Love Island, it is worth 
drawing attention to the fact that male contestants, including Jack and Alex, bond with one another over their pursuit of female contestants. Therefore, in the absence of a woman (in this case Alexandra), some viewers coded Alex as gay. To explain, DeAngelis (2014:3) states: "bromance sustains its identity from the anticipation of a sexual 'something' that will never happen", in the absence of a significant other (woman), doubt may be cast over this. What we see here very clearly is the gaze of the viewing public (Mulvey, 1975) being instrumental in our analysis to allow us to understand how Alex's changing masculinity was seen to threaten the longstanding 'Jani' relationship, which was also confirmed by Dani's own gaze upon fellow character Alex who, when no longer coupled-up, was seen to be leading Dani's own partner (Jack) astray (Arciniega et al., 2008; Flood, 2008; Ging, 2017).

Arguably, the physical intimacy of the bromantic relationship between Jack and Alex was condemned amidst Alex's reluctance to be intimate and to show affection to Alexandra. Again the Mulveyan (Mulvey, 1975) lens of the viewing public's gaze was seen when this closeness between Alex and Jack is noted by viewers, because touching and physicality between men is an act often considered to transgress the performance (Butler, 1988, 1990; Goffman, 1959) of normative gendered expectations (Waitt et al., 2011). Further, through their bromantic conversations with each other, including declarations of love, Alex and Jack can be seen to be failing to comply with the "masculine norms" of "controlling and restricting expression of emotion" (Iwamoto and Smiler, 2013:371). Richardson (2015:158) posits that deepseated emotions are rarely articulated by men; if they are, the man may be accused of being "in touch with his feminine side", thereby going against the "No Sissy Stuff' typology of the Brannon Masculinity Scale (Brannon \& Juni, 1984; David \& Brannon, 1976) masculinities.

There were occasions where Alex can be seen to be "striving to appear heterosexual” (Iwamoto and Smiler, 2013:372), for instance his 'Give 'Em Hell!' (David and Brannon, 1976) masculine obsession with fast cars. Further, through the example of role-play documented above between Alex and Alexandra, Alex can be seen to purposefully create a stage (Goffman, 1959) for his performance of masculinity (see also Day, 2001) drawing on notions of "hard masculinity" (Lyons and Willott, 2008:706). This stage was also set in full view of the fellow characters on the show meaning the performance was public and open to both the gaze and critique of the other performers (Mulvey, 1975), who would later judge how genuine the performance was and comment on whether they thought the Alex ${ }^{2}$ relationship had any longevity. This aligns with 'The Sturdy Oak' category of masculinity from David and Brannon (1976). Thus, by conforming to hegemonic, heterosexual standards for identity, Alex can be seen to be operating within the "heterosexual matrix" (Butler, 1990:151).

As gender and indeed sexuality are performative, and gendered identities do not pre-exist performances of them, identities are, for Butler (1990), profoundly uncertain. The insecurity of gender identity arises precisely because the construction of gender relies on repeated performances (Butler, 1990); as such, there are opportunities to ' $d o$ ' gender differently and therefore be viewed differently by the performers themselves, their fellow performing characters, and the viewing public (Mulvey, 1975). The types of masculinity being performed (see Brannon \& Juni, 1984; David 
\& Brannon, 1976) were also key to understanding how both the fellow characters and the viewing public understood Jack and Alex's heterosexuality and relationship with one another. The labelling of Alex as 'gay' by viewers is significant when considering that "Gayness... is the repository of whatever is symbolically expelled from hegemonic masculinity" (Connell 1995:79). Through our textual analysis we can see "slippage" and transgressions in gender performances by Alex (Butler, 1993:122), and witness an externally imposed gender crisis unfold.

\section{Conclusion}

Through our analysis, we have used the theoretical framing of performance from both Butler (1988; 1990) and Goffman (1959), and theoretical framing of masculinity by the Brannon Masculinity Scale (Brannon \& Juni, 1984; David \& Brannon, 1976), which remains a culturally relevant and analytically valuable tool for assessing masculinity (see Thompson Jr. \& Bennett, 2015). Further, we usefully combined Mulvey's (1975) Male Gaze to our theoretically-informed approach to textual analysis to enable us to explain both the look from the other characters and the look of the viewers.

The cultural adoption of the bromance term represents an increased recognition that men are permitted to have more diverse and homosocial masculine identities (Robinson, White, \& Anderson, 2017). However, as our analysis has uncovered, those homosocial masculine identities come under threat if women surrounding the bromance are removed from the picture. Here, one can see the fragility of the "heterosexual matrix" (Butler, 1990:151), once again showing how masculinity is never far from being contested as being performed in the 'wrong' way. Whilst broadly, this paper contributes to debates on the sociological potential of reality television shows, such as Love Island, itsspecific contribution is to a small, but growing body of international scholarship on homosocial relationships and male love stories in television and film (e.g. Benson, 2017; Brook, 2015; DeAngelis, 2014; Nettleton, 2015; Raphael and Lam, 2017; Sedgwick, 1985). A further contribution of this paper is its demonstration of the application of theory drawn from the social sciences can aid understanding on depictions of gender and relationships in these visual media (see also Silverio, Wilkinson, \&Wilkinson,2020). Using performativity theories (Butler, 1988;1990; Goffman, 1959) as well as a framework for changing and adaptive masculinity (Brannon \& Juni, 1984; David \& Brannon, 1976), along with gathering data using the three lenses of Mulvey's (1975) gaze theory has enabled us to challenge the viewing public's and the fellow characters' assumptions that the 'Jalex' relationship was of homosexual intention, but rather a heterosexual bromance. With this paper and with our focus on the couplings of Jack and Dani and Alex and Alexandra, rather than solely on Jack and Alex themselves, we - responding to Thompson's (2015) call - have contributed towards a redress of the marginalization of women within the study of bromance.

Funding There is no funding associated with this research. 


\section{Declarations}

Conflict of interest The authors declare that the research was conducted in the absence of any commercial or financial relationships that could be construed as a potential conflict of interest.

Ethical Approval This research was not conducted with human subjects, but is an analysis of publicly available material, and so did not require ethical approvals to be sought.

Open Access This article is licensed under a Creative Commons Attribution 4.0 International License, which permits use, sharing, adaptation, distribution and reproduction in any medium or format, as long as you give appropriate credit to the original author(s) and the source, provide a link to the Creative Commons licence, and indicate if changes were made. The images or other third party material in this article are included in the article's Creative Commons licence, unless indicated otherwise in a credit line to the material. If material is not included in the article's Creative Commons licence and your intended use is not permitted by statutory regulation or exceeds the permitted use, you will need to obtain permission directly from the copyright holder. To view a copy of this licence, visit http://creativecommons.org/licen ses/by/4.0/.

\section{References}

Anderson, E. (2005). Orthodox and inclusive masculinity: Competing masculinities among heterosexual men in a feminized terrain. Sociological Perspectives, 48(3), 337-355.

Anderson, P. (2012). Measuring masculinity in an Afro-Caribbean context. Social and Economic Studies, 61(1), 49-93.

Anderson, E., \& McCormack, M. (2018). Inclusive masculinity theory: Overview, reflection and refinement. Journal of Gender Studies, 27(5), 547-561.

Apollon, W. (1993). Four seasons in femininity or four men in a woman's life. Topoi, 12, 101-115.

Arciniega, G. M., Anderson, T. C., Tovar-Blank, Z. G., \& Tracey, T. J. G. (2008). Toward a fuller conception of machismo: Development of a traditional machismo and caballerismo scale. Journal of Counseling Psychology, 55(1), 19-33.

de Beauvoir, S. (2011). The second sex. (C. Borde \& S. Malovany-Chevallier, Trans.) London, United Kingdom: Vintage - The Random House Company. (Original work published 1949).

Bem, S. L. (1974). The measurement of psychological androgyny. Journal of Consulting and Clinical Psychology, 42(2), 155-162.

Benson, C. (2017). At the margins of the bromance: A queer reading of The Hangover III and its promotional material. Film Criticism, 41(1), 1-13.

Brandt, M., \& Carstens, A. (2009). The discourse of the male gaze: A critical analysis of the feature section 'The beauty of sport' in SA Sports Illustrated. Southern African Linguistics and Applied Language Studies, 23(3), 233-243.

Brannon, R., \& Juni, S. (1984). A scale for measuring attitudes about masculinity. Psychology Documents, 14(2612), 6-7.

Brook, H. (2015). Bros before ho(mo)s: Hollywood bromance and the limits of heterodoxy. Men and Masculinities, 18(2), 249-266.

Budgeon, S. (2014). The dynamics of gender hegemony: Femininities, masculinities and social change. Sociology, 48(2), 317-334.

Buckingham, D. (2009). 'Creative' visual methods in media research: Possibilities, problems and proposals. Media, Culture \& Society, 31(4), 633-652.

Butler, J. (1988). Performative acts and gender constitution: An essay in phenomenology and feminist theory. Theatre Journal, 40(4), 519-553.

Butler, J. (1990). Gender trouble: Feminism and the subversion of identity. London: Routledge.

Butler, J. (1993). Bodies that matter. London: Routledge.

Butler, J. (2011). Your behavior creates your gender. [Online], Available: https://www.youtube.com/ watch $? \mathrm{v}=$ Bo7o2LYATDc $\&$ feature=youtu.be [20 January 2019]. 
Cahill, P., \& Papageorgiou, A. (2007). Video analysis of communication in paediatric consultations in primary care. British Journal of General Practice, 57(544), 866-871.

Caldwell, K., \& Atwal, A. (2005). Non-participant observation: Using video tapes to collect data in nursing research. Nurse Researcher, 13(2), 42-54.

Chu, J. Y., Porche, M. V., \& Tolman, D. L. (2005). The adolescent masculinity ideology in relationships scale: Development and validation of a new measure for boys. Men and Masculinities, 8(1), 93-115.

Clarkson, J. (2006). "Everyday Joe" versus "pissy, bitchy, queens": Gay masculinity on StraightActing. com. Journal of Men's Studies, 14(2), 191-207.

Connell, R. (1987). Gender \& power. Cambridge: Polity Press.

Connell, R. (1995). Masculinities. Cambridge: Polity Press.

Corwin, D. P. (2016). The queerness of straight masculinity: Men's emotional intimacies with men in boy meets world and Dawson's creek (unpublished master's dissertation). Fairfax, VA: George Mason University.

David, D. S., \& Brannon, R. (1976). The male sex role: Our culture's blueprint of manhood, and what it's done for us lately. In D. S. David, \& R. Brannon (Eds.), The 49\% majority (pp. 1-48). Reading, MA: Addison-Wesley.

Davis, N. (2014). I love you, hombre: Y tu mamá también as border-crossing bromance. In M. DeAngelis (Ed.), Reading the bromance: Homosocial relationships in film and television (pp. 109-138). Detroit, MI: Wayne State University Press.

Day, K. (2001). Constructing masculinity and women's fear in public space in Irvine, California. Gender, Place and Culture, 8(2), 109-127.

DeAngelis, M. (2014). Introduction. In M. DeAngelis (Ed.), Reading the bromance: Homosocial relationships in television and film (pp. 1-26). Detroit, MI: Wayne State University Press.

Demant, J., \& Järvinen, M. (2006). Constructing maturity through alcohol experience-focus group interviews with teenagers. Addition Research \& Theory, 14(6), 589-602.

Derry, S. J., Pea, R. D., Barron, B., Engle, R. A., Erickson, F., Goldman, R., Hall, R., Kschmann, T., Lemke, J. L., Sherin, M. G., \& Sherin, B. L. (2010). Conducting video research in the learning sciences: Guidance on selection, analysis, technology and ethics. Journal of the Learning Sciences, 19(1), 3-53.

Flood, M. (2008). Men, sex, and homosociality: How bonds between men shape their sexual relations with women. Men and Masculinities, 10(3), 339-359.

Ging, D. (2017). Memes, masculinity and mancession: Love/Hate's online metatexts. Irish Studies Review, 25(2), 170-192.

Ging, D. (2019). Alphas, betas, and incels: Theorizing the masculinities of the manosphere. Men and Masculinities, 22(4), 638-657.

Goffman, E. (1959). The presentation of self in everyday life. London: Penguin Books.

Griffiths, E. B. (2018). Love Island fans turn on Dr Alex as he dumps Alexandra days before the final. Radio Times. Available at: https:/www.radiotimes.com/news/tv/2018-07-27/love-island-fans-turnon-dr-alex-as-he-dumps-alexandra-days-before-the-final/. [Accessed 20/01/2019].

Harder, S. K., \& Demant, J. (2015). Failing masculinity at the club: A poststructural alternative to intoxication feminism. Substance Use \& Misuse, 50(6), 759-767.

ITV plc (2019). Love Island: Available at: https://www.itv.com/loveisland. [Accessed 20/01/2019].

Iwamoto, D. K., \& Smiler, A. P. (2013). Alcohol makes you macho and helps you make friends: The role of masculine norms and peer pressure in adolescent boys' and girls' alcohol use. Substance Use \& Misuse, 48(5), 371-378.

Jackson, B. A. (2012). Bonds of brotherhood: Emotional and social support among college black men. The ANNALS of the American Academy of Political and Social Science, 642(1), 61-71.

Jackson, B. A., \& Wingfield, A. H. (2013). Getting angry to get ahead: Black college men, emotional performance, and encouraging respectable masculinity. Symbolic Interaction, 36(3), 275-292.

Jacobsson, E.-M. (1999). “A female gaze?” Stockholm, Sweden: Centre for User Oriented IT Design, KTH Royal Institute of Technology, Numerical Analysis and Computing Science.

Kilianski, S. E. (2003). Explaining heterosexual men's attitudes toward women and gay men: The theory of exclusively masculine identity. Psychology of Men \& Masculinity, 4(1), 37-56.

Kohlberg, L. (1966). A cognitive-developmental analysis of children's sex-role concepts and attitudes. In E. E. Maccoby (Ed.), The development of sex differences (pp. 82-172). Stanford, CA: Stanford University Press.

Kozinets, R. V. (2010). Netnography. Doing ethnographic research online. Thousand Oaks, CA: SAGE. 
Lewis, A. (2018). Dr Alex's reaction to Alexandra' Hideaway outfit on Love Island was a mess. Available at: https://www.cosmopolitan.com/uk/entertainment/a22526417/love-island-alex-alexandra-hidea way-lingerie-reaction/ [Accessed 03/02/2019].

Lipman-Blumen, J. (1976). Toward a homosocial theory of sex roles: An explanation of the sex segregation of social institutions. Signs: Journal of Women in Culture and Society, 1(3, Part 2), 15-31.

Lupton, B. (2000). Maintaining masculinity: Men who do 'women's work'. British Journal of Management, 11(s1), 33-48.

Lyons, A. C., \& Willott, S. A. (2008). Alcohol consumption, gender identities and women's changing social positions. Sex Roles, 59(9-10), 694-712.

Magrath, R. (2016). Inclusive masculinities in contemporary football: Men in the beautiful game. London: Routledge.

Malbon, B. (1999). Clubbing: Dancing, ecstasy and vitality. London: Routledge.

Mast, J. (2016). Negotiating the 'real' in 'reality shows': production side discourses between deconstruction and reconstruction. Media, Culture \& Society, 38(6), 901-917.

Mulvey, L. (1975). Visual pleasure and narrative cinema. Screen, 16(3), 6-18.

Nettleton, P. H. (2015). Hanging with the boys: Homosocial bonding and bromance coupling in Nip/ Tuck and Boston Legal. In E. Abele \& J. A. Gronsbeck-Tesco (Eds.), Screening images of American masculinity in the age of postfeminism (pp. 120-134). Lanham, MD: Rowman \& Littlefield.

O’Neill, R. (2015). Whither critical masculinity studies? Notes on inclusive masculinity theory, postfeminism, and sexual politics. Men and masculinities, 18(1), 100-120.

Paechter, C. (2006). Masculine femininities/feminine masculinities: Power, identities and gender. Gender and Education, 18(3), 253-263.

Pickard, S. (2018). Age, gender and sexuality through the life course: The girl in time. Abingdon: Routledge.

Poost, A. (2018). Bromance and hookup culture: A study in the performance of masculinity by college men. International Social Science Review, 94(3), 1-38.

Raphael, J., \& Lam, C. (2017). True bromance: The authenticity behind the Stewart/McKellen relationship. Celebrity Studies, 10(2), 153-173.

Renold, E., \& Ringrose, J. (2008). Regulation and rupture: Mapping tween and teenage girls' resistance to the heterosexual matrix. Feminist Theory, 9(3), 313-338.

Richardson, M. J. (2015). Embodied intergenerationality: Family position, place and masculinity. Gender, Place \& Culture: A Journal of Feminist Geography, 22(2), 157-171.

Ripley. (2018). The integration of British undergraduate men's public and private masculinities. Journal of Gender Studies, 27(3), 288-300.

Roberts, B. W. (1997). Plaster or plasticity: Are adult work experiences associated with personality change in women? Journal of Personality, 65(2), 205-232.

Robinson, S., Anderson, E., \& White, A. (2018). The bromance: Undergraduate male friendships and the expansion of contemporary homosocial boundaries. Sex Roles, 78(1-2), 94-106.

Robinson, S., White, A., \& Anderson, E. (2017). Privileging the bromance: A critical appraisal of romantic and bromantic relationships. Men and Masculinities, 22(5), 850-871.

Rokka, J. (2010). Netnographic inquiry and new translocal sites of the social. International Journal of Consumer Studies, 34(4), 381-387.

Schippers, M. (2007). Recovering the feminine other: Masculinity, femininity, and gender hegemony. Theory and Society, 36(1), 85-102.

Schroeder, J. E., \& Zwick, D. (2004). Mirrors of masculinity: Representation and identity in advertising images. Consumption, Markets \& Culture, 7(1), 21-52.

Searle, J. (1979). Expression and meaning: Studies in the theory of speech acts. Cambridge: Cambridge University Press.

Sedgwick, E. K. (1985). Between men: English literature and male homosocial desire. New York, NY: Columbia University Press.

Skeggs, B. (2009). The moral economy of person production: The class relations of self-performance on 'reality' television. The Sociological Review, 57(4), 627-644.

Skeggs, B., \& Wood, H. (2008). The labour of transformation and circuits of value 'around' reality television. Continuum: Journal of Media \& Cultural Studies, 22(4), 559-572.

Silverio, S. A. (2018). A new outlook: We need an academic debate on the question of gender. Mensa Magazine, (8), 23-25.

Silverio, S. A. (2019). Reconstructing gender to transcend shame: Embracing human functionality to enable agentic and desexualised bodies. In C.-H. Mayer \& E. Vanderheiden (Eds.), The bright 
side of shame. Transforming and growing through practical applications in cultural contexts. Cham, Switzerland: Springer.

Silverio, S. A., Wilkinson, C., \& Wilkinson, S. (2020). Further uses for grounded theory: A methodology for psychological studies of the performing arts, literature, and visual media. Qualitative Methods in Psychology Bulletin, (29), 8-19.

Spencer, S. (2010). Visual research methods in the social sciences: Awakening visions. London: Routledge.

Sturken, M., \& Cartwright, L. (2001). Practices of looking. An introduction to visual culture. Oxford: Oxford University Press.

Thompson, L. (2015). Book Review: Reading the bromance: Homosocial relationships in film and television. Journal of Gender Studies, 24(3), 368-370.

Thompson, E. H. Jr., \& Bennett, K. M. (2015). Measurement of masculinity ideologies: A (critical) review. Psychology of Men \& Masculinity, 16(2), 115.

von Benzon, N. (2018). Informed consent and secondary data: Reflections on the use of mothers' blogs in social media research. Area, 51(1), 182-189.

Wade, J. C., \& Donis, E. (2007). Masculinity ideology, male identity, and romantic relationship quality among heterosexual and gay men. Sex Roles, 57(9-10), 775-786.

Waitt, G., Jessop, L., \& Gorman-Murray, A. (2011). 'The guys in there just expect to be laid': The embodied and gendered socio-spatial practices of a 'night out' in Wollongong Australia. Gender, Place \& Culture: A Journal of Feminist Geography, 18(2), 255-275.

Wilkinson, C., \& von Benzon, N. (2021). Selecting and analyzing publicly generated online content. In N. von Benzon, M. Holton, C. Wilkinson, \& S. Wilkinson (Eds.), Creative methods for human geographers (pp. 325-336). London: Sage.

Wilkinson, C. (2017). Going 'backstage': Observant participation in research with young people. Children's Geographies, 15(5), 614-620.

Wilkinson, S. (2019). The story of Samantha: The teaching performances and inauthenticities of an early career human geography lecturer. Higher Education Research \& Development, 38(2), 398-410.

Publisher's note Springer Nature remains neutral with regard to jurisdictional claims in published maps and institutional affiliations.

\section{Authors and Affiliations}

\section{Sergio A. Silverio ${ }^{1,2} \oplus \cdot$ Catherine Wilkinson $^{3}\left[\right.$ - Samantha Wilkinson ${ }^{4}[$}

1 Department of Women \& Children's Health, King's College London, Research Office 4, 10th Floor North Wing, St. Thomas' Hospital, Westminster Bridge Road, London SE1 7EH, Lambeth, UK

2 Department of Psychology, University of Liverpool, Liverpool, UK

3 School of Education, Liverpool John Moores University, Liverpool, UK

4 School of Childhood, Youth and Education Studies, Manchester Metropolitan University, Manchester, UK 